\title{
Proposal to Reject the Specific Epithet marianum in the Name Mycobacterium marianum Penso 1953 and to Conserve the Specific Epithet scrofulaceum in the Name Mycobacterium scrofulaceum Prissick and Masson 1956 Request for an Opinion \\ LAWRENCE G. WAYNE
}

Veterans Administration Hospital, Long Beach, California 90801, and California College of Medicine, University of California, Irvine, California 92664

\begin{abstract}
Reasons have been published for considering Mycobacterium marianum Penso 1953 and $M$. scrofulaceum Prissick and Masson 1956 to be subjective synonyms. Although the name $M$. marianum was validly published before $M$. scrofulaceum, it is proposed that $M$. marianum be rejected as a nomen perplexum because of its orthographic similarity to $M$. marinum Aronson 1926. Instances of confusion due to the similarity of the names are documented.
\end{abstract}

Wayne and Lessel (10) reviewed evidence which supports the conclusion that Mycobacterium marianum Penso 1953 and $M$. scrofulaceum Prissick and Masson 1956 should be regarded as subjective synonyms. They concluded that $M$. marianum, although it was published (5) before $M$. scrofulaceum (6), should be rejected as an orthographic variant of $M$. marinum Aronson 1926, under Rule 27 of the International Code of Nomenclature of Bacteria (3), which covers a case wherein two names are so similar as to cause confusion.

Subsequent to that proposal, Wayne et al. (8) presented further evidence for the subjective synonymy of $M$. marianum and $M$. scrofulaceum, based on a large pool of data from an international cooperative study. Documentation is presented of the confusion associated with the existence of the names $M$. marianum and $M$. marinum, and it is requested that the name $M$. marianum be rejected and the name $M$. scrofulaceum be conserved.

The documentation is based on the author's experiences and on material submitted by other investigators, at the suggestion of the Subcommittee for Mycobacterium of the International Committee on Systematic Bacteriology, which endorsed the proposal here presented (E. H. Runyon, personal communication).

(i) (Lawrence G. Wayne) In two instances, galley proofs were received in which $M$. marinum was set where $M$. marianum had actually appeared in the original manuscript. In one of these papers (10), the error was detected in proof and cited in a letter dated May 26, 1969, to Lucile Myers, secretary to R. E. Buchanan, who was then editor of this journal. In the other paper (9), the error escaped attention in proof and appeared in the caption to Fig. 4. This error was pointed out in subsequent correspondence (7).

(ii) (Lawrence G. Wayne) In a letter dated February 26, 1969, over the signature of R. E. Buchanan, then editor of this journal, the following statement appears: "The manuscript, 'On the Synonomy of Mycobacterium marinum (sic) Penso 1953 and Mycobacterium scrofulaceum Prissick and Masson 1956, and the Resolution of a Nomenclatural Problem' by Wayne and Lessel has been accepted for publication..." Even so scrupulous a nomenclaturist as Prof. Buchanan failed to note that the second "a" had been dropped from "marianum" in his letter!

(iii) (Ernest H. Runyon) For nine years, 1956-1965, a strain in the National Collection of Type Cultures, London, was listed as $M$. marinum when actually it was (and is) $M$. marianum.

This strain, 8138, was received in 1950 from Penso, whose designation of it was simply "Battaglini." The designation " $M$. marinum" resulted from a report, 1956, by Cowan of Ruth Gordon's findings. She has now no record of what identification she gave Cowan, but her recorded data do not in any way indicate the species $M$. marinum. In 1965 , C. H. Collins found that strain 8138 could not be $M$. marinum (being a scotochromogen, growing at $44 \mathrm{C}$, but very poorly at $22 \mathrm{C}$ ). Consequently, in the current NCTC catalog the species designation is as it was before 1956: "M. sp.," with the name 
$M$. marinum in the right-hand column, which is intended to indicate the name under which the strain was originally deposited. Bojalil et al. (2) identified strain 8138 as $M$. marianum, and unquestionably this is its proper designation. Bojalil wrongly ascribed the strain to the ATCC; ATCC 8138 (no longer carried) was the fungus Microsporum gypseum. It is no longer possible to identify the point at which the error in transcription of the name occurred.

(iv) (Hugo L. David) (Dr. David is Chief of the Mycobacteriology section of the Center for Disease Control of the U.S. Public Health Service and has responsibility for identification of referred mycobacterial cultures and distribution of certain mycobacterial antigens.) We feel that the adoption of $M$. marianum instead of $M$. scrofulaceum is a very poor choice. To retrieve the letters in which confusion between $M$. marianum and $M$. marinum is apparent is not very easy because our correspondence is filed by states and not by subject matter. I only say that the problem is a real one, and I would like to call your attention to another aspect that concerns us. This is the use of skin-testing antigens by physicians not necessarily familiar with bacterial nomenclature. PPD-G is the antigen prepared from $M$. scrofulaceum (strain Gause), and I am convinced that the change of $M$. scrofulaceum to $M$. marianum will cause great confusion. A typing error (marianum vs. marinum) in a formal request will lead to the furnishing of the wrong antigen. Since we are distributing these products, I view with great concern the adoption of the name $M$. marianum.

(vi) (Lawrence G. Wayne and George P. Kubica) We both have encountered confusion between $M$. marianum and $M$. marinum in verbal discussions and have an especially vivid memory of a round table discussion on mycobacterial taxonomy in Chicago in May 1959. After several hours during which both terms had been used, one conferee rose in puzzlement to ask which organism we had been discussing, and it became apparent that some had been talking about $M$. marinum and others about $M$. marianum without it becoming clear who was talking about which and when.

In sum, it is apparent that confusion can and does arise between the names $M$. marianum and $M$. marianum. Furthermore, the confusion is especially significant because both organisms produce human disease, but the management of these diseases differs. There is no question that $M$. marinum was validly published (1) before $M$. marianum, so there is no need to request conservation of $M$. marinum; it is already a legitimate name. Although $M$. marianum is not an etymologic variant of $M$. marinum, the orthographic variance is so slight as to assure confusion. In fact, it is of interest that Lapage et al. (4) used $M$. marinum and $M$. marianum to illustrate the situation where a perplexing name (nomen perplexum) might be rejected under rules 53 and $57 \mathrm{c}$ of their proposed revision of the International Code of Nomenclature of Bacteria. There appears to be sufficient documentation of the subjective synonymy of $M$. scrofulaceum and $M$. marianum to justify adoption of the former name. Accordingly, an Opinion is requested from the Judicial Commission that the specific epithet marianum in the name Mycobacterium marianum Penso 1953 be rejected and that the specific epithet scrofulaceum in the name Mycobacterium scrofulaceum Prissick and Masson 1956 be conserved.

\section{REPRINT REQUESTS}

Address reprint requests to: Dr. Lawrence G. Wayne, Veterans Administration Hospital, 5901 E. 7th St., Long Beach, Calif. 90801.

\section{LITERATURE CITED}

1. Aronson, J. D. 1926. Spontaneous tuberculosis in salt water fish. J. Infect. Dis. 39:315-320.

2. Bojalil, L. F., J. Cerbon, and A. Trujillo. 1962. Adansonian classification of mycobacteria. J. Gen. Microbiol. 28:333-346,

3. International Code of Nomenclature of Bacteria. 1966. Int. J. Syst. Bacteriol. 16:459-490.

4. Lapage, S. P., W. A. Clark, E. F. Lessel, H. P. R. Seeliger, and P. H. A. Sneath. 1973. Proposed revision of the International Code of Nomenclature of Bacteria. Int. J. Syst. Bacteriol. 23:83-108.

5. Penso, G. 1953. Criteri generali par determinare la posizione sistematica di un micobatterio. VI. Congr. Int. Microbiol: Atti del V Symposium: Actinomycetales, morfologia, Biologia e Sistematica, p. 89-101. Istituto Superiore di Sanita, Rome.

6. Prissick, F. H., and A. M. Masson. 1956. Cervical lymphadenitis in children caused by chromogenic mycobacteria. Can. Med. Assoc. J. 75:798-803.

7. Wayne, L. G. 1968. M. marinum and M. marianum. Am. Rev. Resp. Dis. 98:317.

8. Wayne, L. G., T. M. Dietz, C. Gernez-Rieux, P. A. Jenkins, W. Kappler, G. P. Kubica, J. B. G. Kwapinski, G. Meissner, S. R. Pattyn, E. H. Runyon, K. H. Schröder, V. A. Silcox, A. Tacquet, M. Tsukamura, and E. Wolinsky. 1971. A cooperative numerical analysis of scotochromogenic slowly growing mycobacteria. J. Gen. Microbiol. 66:255-271.

9. Wayne, L. G., J. R. Doubek, and G. A. Diaz. 1967. Classification and identification of mycobacteria. IV. Some important scotochromogens. Am. Rev. Resp. Dis. 96: 88-95.

10. Wayne, L. G., and E. F. Lessel. 1969. On the synonymy of Mycobacterium marianum. Penso 1953 and Mycobacterium scrofulaceum Prissick and Masson 1956 and the resolution of a nomenclatural problem. Int. J. Syst. Bacteriol. 19:257-261. 